\title{
Quality of life in schizophrenic patients: the influence of sociodemographic and clinical characteristics and satisfaction with social support
}

\author{
Qualidade de vida nas pessoas com esquizofrenia: a influência das \\ características sociodemográficas e clínicas e da satisfação com o suporte social
}

Lara Manuela Guedes de Pinho, ${ }^{1}$ Anabela Maria de Sousa Pereira, ${ }^{1}$ Cláudia Margarida Correia Balula Chaves ${ }^{2}$

\begin{abstract}
Objective: To evaluate the relationship of sociodemographic and clinical characteristics and satisfaction with social support with the quality of life of schizophrenic patients.

Methodology: This study included a sample of 268 participants. An interview was conducted to obtain sociodemographic and clinical data, supplemented with two assessment tools used to evaluate quality of life (World Health Organization Quality of Life instrument-Abbreviated version - WHOQOL-Bref) and satisfaction with social support (Social Support Satisfaction Scale - SSSS). Descriptive and inferential analyses were performed.

Results: Most individuals were male (63.4\%), with a mean age of 45.4 years, single $(85.4 \%)$, living with their family $(62.3 \%)$ and unemployed $(90.3 \%)$. As for clinical characteristics, most had the disease for less than 20 years $(50.7 \%)$, and $55.6 \%$ had at least one hospitalization within the last 5 years. Being employed and having had no hospitalization within the last 5 years were positively correlated with one or more WHOQOL-Bref domains. The results of the variables intimacy $(p<0.001)$ and satisfaction with friends $(p<0.001)$ were independently related to the total WHOQOL-Bref score.

Conclusion: Having a job, having had no hospitalization within the last 5 years and having greater satisfaction with social support are factors that positively influence quality of life among schizophrenics. It is therefore crucial that the psychosocial rehabilitation of patients with schizophrenia take these factors into account, increasing the support network, preventing relapses and promoting occupational activities.
\end{abstract}

Keywords: Schizophrenia, quality of life, social support, demographic data.

\section{Resumo}

Objetivo: Avaliar a relação entre as características sociodemográficas e clínicas e a satisfação com o suporte social com a qualidade de vida dos doentes com esquizofrenia.

Métodos: A amostra do estudo é de 268 participantes. Foi realizada uma entrevista para obter os dados sociodemográficos e clínicos e aplicados dois questionários para avaliar a qualidade de vida (World Health Organization Quality of Life instrumentAbbreviated version - WHOQOL-Bref) e a satisfação com o suporte social (Escala de Satisfação com o Suporte Social ESSS). Foram efetuadas análises descritivas e inferenciais.

Resultados: A maioria dos indivíduos era do gênero masculino $(63,4 \%)$, com uma média de idade de 45,4 anos, solteiros $(85,4 \%)$, vivendo com a família $(62,3 \%)$ e desempregados $(90,3 \%)$. Relativamente às características clínicas, $50,7 \%$ tinham a doença há menos de 20 anos, e 55,6\% estiveram internados pelo menos uma vez nos últimos 5 anos. Os resultados demonstraram que estar empregado e não ter sido internado nos últimos 5 anos estão positivamente relacionados com um ou mais domínios da WHOQOL-Bref. A satisfação com a intimidade $(p<0,001)$ e a satisfação com os amigos $(p<0,001)$ foram independentemente associados ao escore total da WHOQOL-Bref.

Conclusão: Ter emprego, não ter hospitalizações nos últimos 5 anos e estar satisfeito com o suporte social são fatores que influenciam positivamente a qualidade de vida dos doentes com esquizofrenia. Por conseguinte, é crucial que esses fatores sejam levados em conta nos programas de reabilitação com o suporte social, aumentando a rede de suporte, evitando recaídas e promovendo atividades ocupacionais.

Descritores: Esquizofrenia, qualidade de vida, suporte social, dados demográficos.

\footnotetext{
${ }^{1}$ Departamento de Educação e Psicologia, Centro de Investigação "Didática e Tecnologia na Formação de Formadores" (CIDTFF), Centro de Investigação em Tecnologias e Serviços de Saúde (CINTESIS), Universidade de Aveiro, Aveiro, Portugal. ${ }^{2}$ Escola Superior de Saúde de Viseu, Instituto Politécnico de Viseu (IPV), Centro de Estudos em Educação, Tecnologias e Saúde (CI\&DETS), Viseu, Portugal.

This article is part of the first author's final dissertation, entitled "Quality of life in schizophrenia: contributions to the paradigm shift," written for the Psychology Doctoral Program, which is being concluded at the Department of Education and Psychology of Universidade de Aveiro under the guidance of Profs. Anabela Pereira and Cláudia Chaves, coauthors of this manuscript.

Submitted Jan 10 2017, accepted for publication Sep 252017.

Suggested citation: Guedes de Pinho LM, Pereira AM, Chaves CM. Quality of life in schizophrenic patients: the influence of sociodemographic and clinical characteristics and satisfaction with social support. Trends Psychiatry Psychother. 2018;40(3):202-209. http://dx.doi.org/10.1590/2237-6089-2017-0002
} 


\section{Introduction}

Schizophrenia is a severe mental disorder and it is associated with significant social and occupational dysfunctions. Studies show that over $80 \%$ of people with schizophrenia have a relapse after their first stay at a hospital. ${ }^{1}$ In a recent study of a sample of 808 patients with schizophrenia admitted to a hospital for the first time, $70.5 \%$ were readmitted within 10 years, with a mean of 1.9 years elapsed in-between admissions. Also, $25 \%$ of the patients were readmitted within 4 months of their first stay. ${ }^{2}$ The risk of recurrence is associated with symptoms, family support, insight and comorbidities. . $^{3,4}$

As referred to in the Diagnostic and Statistical Manual of Mental Disorders, 5th edition (DSM-5), when individuals who are socially active withdraw from social activities, this is often the first sign of the disease. ${ }^{5}$ Depending on the age at the onset of illness, individuals with schizophrenia may not be able to learn certain social skills. Even when these skills have been acquired, they may be lost due to the symptomatology. For this reason, these patients often have marked social deficits, which may include difficulty in social relationships or in playing social roles (husband/wife, employee), for example. ${ }^{6}$ Consequently, many of these patients do not marry or have limited social contacts outside their family environment. ${ }^{5}$

Besides social functioning, social support is also crucial and may influence quality of life for people with schizophrenia, because it increases the ability of patients to adapt to their daily lives and stressful events. Therefore, patients who have a social support network have better living conditions, lower incidence of symptoms and fewer hospital admissions than those who lack this support.?

There are several studies which indicate that patients with schizophrenia have a lower quality of life. ${ }^{8}$ Most recent studies on these patients' quality of life focus on the influence of psychotic symptoms, depressive symptoms, neurocognition and social functioning. ${ }^{9-12}$ Thus, we wanted to go further and focus on the satisfaction of the person with schizophrenia with regard to their social support, e.g.: satisfaction with family, friends, intimate relationships and social activities. Our intention was to find out whether these variables influence subjective quality of life. In addition, since there are few studies that investigate the quality of life of people with schizophrenia in Portugal, and sociodemographic and clinical characteristics may differ from country to country, we also analyzed these characteristics, correlating them with subjective quality of life. Therefore, the aim of this investigation was to evaluate the sociodemographic and clinical characteristics, as well as satisfaction with social support, of Portuguese patients with schizophrenia and examine their relationship with quality of life.

Considering the aims of this study, we formulated the following hypotheses: $\mathrm{H} 1$ - some sociodemographic characteristics influence the quality of life of patients with schizophrenia; $\mathrm{H} 2$ - the longer the duration of schizophrenia, the worse the quality of life; H3 - the higher the number of hospitalizations in psychiatric units, the worse the quality of life of schizophrenic patients; H4 - participation in psychosocial rehabilitation programs improve the quality of life of schizophrenic patients; and H5 - satisfaction with social support improves the quality of life of schizophrenic patients.

Knowledge of the determining factors of quality of life in people with schizophrenia can help professionals choose the most appropriate methods and more effective interventions. ${ }^{9}$ Thus, we hope that this study will contribute to adapting intervention strategies at psychosocial rehabilitation services, taking into account factors that are favorable to improving quality of life.

\section{Method}

This is a descriptive epidemiological, cross-sectional, observational study.

\section{Participants}

A non-probabilistic, convenience sample of participants was selected, consisting of patients diagnosed with schizophrenia (according to criteria from the International Classification of Diseases, Tenth Revision - ICD-10) receiving treatment at the psychiatry services of eight hospitals in Portugal (five public and three private) and agreeing to participate in the study voluntarily. The subjects were referred to us by their psychiatrist. Patients diagnosed with mental retardation and patients with active psychotic symptoms preventing understanding of the questionnaires were excluded from the study.

A total of 337 patients with schizophrenia who met the criteria were contacted and 69 refused to participate. Thus, the sample consisted of 268 participants of both genders, aged $20-78$ years (mean \pm standard deviation $=46 \pm 12.81$ ). Of the 268 participants, 136 were enrolled in outpatient services, 68 in psychosocial rehabilitation services, and 64 were hospitalized ( 28 in acute inpatient stabilization phase, and 36 institutionalized).

To calculate the power of the sample, we analyzed the mean of number of participants in eight similar studies, and the result was $n=256$. We therefore consider that the power of our sample, with $n=268$, is above average. The data were collected in 2015. 


\section{Instruments}

An interview was conducted to obtain sociodemographic and clinical data. In order to characterize the participants, the following data were obtained: gender, age, duration of psychiatric disorder, marital status, cohabitation, educational level, employment, participation in psychosocial rehabilitation program, number of hospitalizations in psychiatric units and number of hospitalizations in the last 5 years.

The aim of the World Health Organization Quality of Life instrument (WHOQOL) is to evaluate quality of life, as defined by the World Health Organization (WHO). In the present study, the abbreviated version was used (WHOQOL-Bref). It consists of 26 items organized into four areas: physical health, psychological, social relationships and environment. In addition to these domains, the instrument also contains a general aspect. The instrument's questions were formulated using four 5-point Likert response scales (intensity, capacity, frequency and evaluation), listed either negatively or positively. Results were evaluated on a scale from 0 to $100 .{ }^{13}$ The instrument was found to be internally consistent, as the Cronbach's alpha was 0.87.

The Social Support Satisfaction Scale (SSSS) has been validated for the Portuguese population. ${ }^{14}$ This questionnaire consists of 15 questions, each assessed using a 5-point Likert scale and consisting of four areas: satisfaction with friends, intimacy, satisfaction with family and social activities. Results were converted to a scale from 0 to 100 . The instrument was found to be internally consistent, as the Cronbach's alpha was 0.86 .

\section{Ethical procedures and data collection}

After approval by Comissão Nacional de Protecção de Dados (CNPD), the Portuguese data protection authority (approval notification no. 843/2015) as well as the ethics committees of the various Portuguese institutions where the study was conducted, data collection initiated.

All the necessary information was provided to all participants, who were asked to sign an informed consent form. Their anonymity and confidentiality of the data collected were assured. Patients were informed that their participation was entirely voluntary and that they could quit at any time.

The data were collected through individual interviews with the participants conducted by the researchers and lasting approximately 30 minutes. The questionnaires were applied in a private office. After completing the interviews, the participant's psychiatrist was asked to provide access to the patient's clinical record so that any missing data could be retrieved.

\section{Statistical analysis}

The data were analyzed using the Statistical Package for Social Sciences (SPSS ${ }^{\circledR}$ ) version 24.0 for Windows.

Sociodemographic and clinical data as well as WHOQOL-Bref and SSSS results underwent statistical analysis by descriptive statistics (frequency, mean and standard deviation). The Student t-test or analysis of variance (ANOVA) parametric tests were performed as appropriate, so as to compare the subgroups of independent variables related to sociodemographic and clinical data and the results of the WHOQOL-Bref scale. In order to analyze the correlation between quality of life and satisfaction with social support variables, the Pearson correlation coefficient was calculated. A multiple regression analysis using the enter method was applied to determine which SSSS dimensions by themselves explained the total score of the WHOQOL-Bref scale, defined as the dependent variable. Tukey's post-hoc test was also performed to control for type 1 error.

\section{Results}

The sociodemographic, clinical, quality of life and satisfaction with social support data are presented in Table 1.

Most participants were male (63.4\%), aged $20-78$ years, with a mean age of $45.4 \pm 12.8$ years. A high percentage of the participants were single $(85.4 \%)$, lived with their family $(62.3 \%)$ and were unemployed (90.3\%). Also, $7.8 \%$ reported never having been hospitalized.

Regarding the WHOQOL-Bref questionnaire, mean values obtained for each of the domains were analyzed, and the standard deviation was calculated. Means were evaluated using a scale from 0 to 100 . The domain with the highest score was found to be physical $(x=63.29$ ) and the one with the lowest score, social relationships $(x=53.86)$.

As for SSSS results, the highest satisfaction scores were obtained with the family $(x=63.15)$, and the worst with friends $(x=46.79)$.

Having performed the ANOVA and the Student t-test, as appropriate, the results of the WHOQOL-Bref scale did now show statistically significant differences in relation to the variables age, duration of psychiatric disorder, educational level, marital status, cohabitation, number of hospitalizations in psychiatric units and participation in psychosocial rehabilitation program.

The predictor variables employment status, gender and hospitalization in the last 5 years were associated with some WHOQOL-Bref domains in the Student t-test 
Table 1 - Sociodemographic and clinical characteristics, quality of life, satisfaction with social support in 268 patients with schizophrenia

\begin{tabular}{|c|c|}
\hline Variable & Sample $(n=268)$ \\
\hline \multicolumn{2}{|l|}{ Gender } \\
\hline Female & $98(36.6)$ \\
\hline Male & $170(63.4)$ \\
\hline Age & $45.4 \pm 12.8$ \\
\hline \multicolumn{2}{|l|}{ Duration of psychiatric disorder } \\
\hline$<20$ years & $136(50.7)$ \\
\hline$>20$ years & $132(49.3)$ \\
\hline \multicolumn{2}{|l|}{ Educational level } \\
\hline 4 years of schooling & $67(25)$ \\
\hline 6 or 9 years of schooling & $128(47.8)$ \\
\hline High school (12 years of schooling) & $53(19.8)$ \\
\hline University education & $20(7.5)$ \\
\hline \multicolumn{2}{|l|}{ Marital status } \\
\hline Married & $39(14.6)$ \\
\hline Single & $229(85.4)$ \\
\hline \multicolumn{2}{|l|}{ Cohabitation } \\
\hline Family & $167(62.3)$ \\
\hline Other & $101(37.7)$ \\
\hline \multicolumn{2}{|l|}{ Employment status } \\
\hline Yes & $26(9.7)$ \\
\hline No & $242(90.3)$ \\
\hline \multicolumn{2}{|l|}{ Number of hospitalizations in psychiatric units } \\
\hline Never hospitalized & $21(7.8)$ \\
\hline Only once & $61(22.8)$ \\
\hline 2 to 5 times & $124(46.3)$ \\
\hline$>5$ times & $62(23.1)$ \\
\hline \multicolumn{2}{|l|}{ Hospitalization in the last 5 years } \\
\hline Yes & $149(55.6)$ \\
\hline No & $119(44.4)$ \\
\hline \multicolumn{2}{|l|}{ Psychosocial rehabilitation program } \\
\hline Yes & $150(56)$ \\
\hline No & $118(44)$ \\
\hline WHOQOL-Bref physical health & $63.3 \pm 16.7$ \\
\hline WHOQOL-Bref psychological health & $62.7 \pm 17.3$ \\
\hline WHOQOL-Bref social relationships & $53.9 \pm 22.1$ \\
\hline WHOQOL-Bref environment & $60.8 \pm 14.5$ \\
\hline WHOQOL-Bref overall quality of life/general health & $56.6 \pm 22.2$ \\
\hline WHOQOL-Bref total score & $59.5 \pm 15.1$ \\
\hline SSSS satisfaction with friends & $46.8 \pm 33.0$ \\
\hline SSSS intimacy & $49.8 \pm 24.2$ \\
\hline SSSS satisfaction with family & $63.2 \pm 33.4$ \\
\hline SSSS satisfaction with Social activities & $49.4 \pm 28.6$ \\
\hline SSSS total score & $51.4 \pm 21.5$ \\
\hline
\end{tabular}

Data presented as $\mathrm{n}(\%)$ or mean \pm standard deviation.

SSSS = Social Support Satisfaction Scale; WHOQOL-Bref = World Health Organization Quality of Life instrumentAbbreviated version. 
comparison. Employed respondents showed higher scores in the WHOQOL-Bref scale in all areas compared to unemployed ones, with statistically significant results for the physical $(p=0.014)$, psychological $(p=0.026)$ and environmental $(p=0.026)$ domains, as well as for the total score $(p=0.020)$. Male subjects showed statistically significant differences compared to females only in the psychological domain $(p=0.039)$, with higher results. Patients who had not been hospitalized in the last 5 years obtained better results than those who had in the environmental $(p<0.001)$ and general health $(p=0.001)$ domains as well as in the total scale score $(p=0.002)$ (Table 2).

Pearson's correlation coefficient showed a positive relationship between WHOQOL-Bref and SSSS in all domains (Table 3).

Multiple linear regression was performed between the total WHOQOL-Bref score and the various domains of the SSSS to identify which variables were independently related to quality of life (Table 4). According to the ANOVA test, the model was significant $(p<0.001)$ and the variables explained $38.9 \%$ of the relationship, with

Table 2 - Sociodemographic and clinical variables and WHOQOL-Bref domains

\begin{tabular}{|c|c|c|c|c|c|c|c|}
\hline Variable & $\mathbf{n}$ & Physical & Psychological & Social & Environment & General & Total \\
\hline \multicolumn{8}{|c|}{ Employment status } \\
\hline Yes & 26 & $70.9 \pm 17.9$ & $69.9 \pm 17.1$ & $60.6 \pm 24.4$ & $66.8 \pm 12.7$ & $61.5 \pm 23.2$ & $65.9 \pm 16.3$ \\
\hline \multirow[t]{2}{*}{ No } & 242 & $62.5 \pm 16.4$ & $61.9 \pm 17.2$ & $53.1 \pm 21.8$ & $60.2 \pm 14.6$ & $56.1 \pm 22.1$ & $58.8 \pm 14.8$ \\
\hline & & $\begin{array}{c}t=2.463 \\
p=0.014 *\end{array}$ & $\begin{array}{c}\mathrm{t}=2.245 \\
\mathrm{p}=0.026^{*}\end{array}$ & $\begin{array}{l}t=1.490 \\
p=0.147\end{array}$ & $\begin{array}{c}\mathrm{t}=2.232 \\
\mathrm{p}=0.026^{*}\end{array}$ & $\begin{array}{l}\mathrm{t}=1.201 \\
\mathrm{p}=0.231\end{array}$ & $\begin{array}{c}\mathrm{t}=2.331 \\
\mathrm{p}=0.020^{*}\end{array}$ \\
\hline \multicolumn{8}{|l|}{ Gender } \\
\hline Female & 98 & $62.3 \pm 17.8$ & $59.6 \pm 19.9$ & $53.8 \pm 23.6$ & $61.2 \pm 15.2$ & $56.1 \pm 23.8$ & $58.6 \pm 16.6$ \\
\hline \multirow[t]{2}{*}{ Male } & 170 & $63.8 \pm 16.1$ & $64.5 \pm 15.4$ & $53.9 \pm 21.3$ & $60.6 \pm 14.1$ & $56.8 \pm 21.2$ & $59.9 \pm 14.1$ \\
\hline & & $\begin{array}{l}\mathrm{t}=-0.720 \\
\mathrm{p}=0.472\end{array}$ & $\begin{array}{l}\mathrm{t}=-2.078 \\
\mathrm{p}=0.039 *\end{array}$ & $\begin{array}{l}t=-0.016 \\
p=0.987\end{array}$ & $\begin{array}{l}t=0.326 \\
p=0.745\end{array}$ & $\begin{array}{l}\mathrm{t}=0.254 \\
\mathrm{p}=0.800\end{array}$ & $\begin{array}{l}\mathrm{t}=-0.684 \\
\mathrm{p}=0.494\end{array}$ \\
\hline \multicolumn{8}{|c|}{ Hospitalization in last 5 years } \\
\hline Yes & 149 & $61.7 \pm 18.1$ & $61.3 \pm 18.1$ & $51.9 \pm 22.8$ & $57.6 \pm 15.8$ & $52.5 \pm 23.4$ & $57.0 \pm 16.3$ \\
\hline \multirow[t]{2}{*}{ No } & 119 & $65.3 \pm 14.7$ & $64.4 \pm 16.3$ & $56.4 \pm 21.1$ & $64.9 \pm 11.6$ & $61.7 \pm 19.4$ & $62.5 \pm 12.7$ \\
\hline & & $\begin{array}{l}\mathrm{t}=-1.762 \\
\mathrm{p}=0.079\end{array}$ & $\begin{array}{l}\mathrm{t}=-1.444 \\
\mathrm{p}=0.150\end{array}$ & $\begin{array}{l}t=-1.670 \\
p=0.096\end{array}$ & $\begin{array}{l}\mathrm{t}=-4.354 \\
\mathrm{p}=0.000^{+}\end{array}$ & $\begin{array}{l}t=-3.491 \\
p=0.001^{+}\end{array}$ & $\begin{array}{l}\mathrm{t}=-3.105 \\
\mathrm{p}=0.002^{+}\end{array}$ \\
\hline
\end{tabular}

Correlation significant at $* 0.05$ and ${ }^{+} 0.01$ (Pearson correlation coefficient).

WHOQOL-Bref $=$ World Health Organization Quality of Life instrument-Abbreviated version.

Table 3 - Correlations of WHOQOL-Bref and SSSS domains $(n=268)$

\begin{tabular}{|c|c|c|c|c|c|}
\hline & Physical & Psychological & Social & Environment & General \\
\hline Satisfaction with friends & $0.408^{+}$ & $0.384^{+}$ & $0.502^{+}$ & $0.359^{+}$ & $0.335^{+}$ \\
\hline Intimacy & $0.428^{+}$ & $0.468^{+}$ & $0.513^{+}$ & $0.511^{+}$ & $0.432^{+}$ \\
\hline Satisfaction with family & $0.162 *$ & $0.184^{+}$ & $0.258^{+}$ & $0.316^{+}$ & $0.210^{+}$ \\
\hline Satisfaction with social activities & $0.206^{+}$ & $0.236^{+}$ & $0.242^{+}$ & $0.361^{+}$ & $0.297^{+}$ \\
\hline SSSS total score & $0.441^{+}$ & $0.456^{+}$ & $0.554^{+}$ & $0.530^{+}$ & $0.445^{+}$ \\
\hline
\end{tabular}

Correlation significant at $* 0.05$ and ${ }^{+} 0.01$ (Pearson correlation coefficient).

SSSS $=$ Social Support Satisfaction Scale; WHOQOL-Bref $=$ World Health Organization Quality of Life instrument-Abbreviated version .

Table 4 - SSSS domains associated with the WHOQOL-Bref total score

\begin{tabular}{lccccc}
\hline & $\mathbf{R}$ & $\mathbf{R}^{\mathbf{2}}$ & Beta & t & p-value \\
\hline Satisfaction with friends & & & 0.227 & 3.851 & 0.000 \\
Intimacy & & & 0.390 & 6.259 & 0.000 \\
Satisfaction with family & 0.624 & 0.389 & 0.073 & 1.412 & 0.159 \\
Satisfaction with social activities & & & 0.096 & 1.823 & 0.069 \\
\hline
\end{tabular}

SSSS = Social Support Satisfaction Scale; WHOQOL-Bref = World Health Organization Quality of Life instrument-Abbreviated version.

206 - Trends Psychiatry Psychother. 2018;40(3) 
the most important variable being intimacy (beta = $0.390)$. The variables intimacy and satisfaction with friends were independently related to the WHOQOL-Bref total score: the greater the intimacy and satisfaction with friends, the higher the quality of life. These results were confirmed by Tukey's post-hoc test. Satisfaction with family and satisfaction with social activities did not yield significant results in the regression model.

\section{Discussion}

For a better understanding of the results obtained, we chose to analyze them taking into account the hypotheses formulated for this study.

Analyzing the results of the sociodemographic characterization $(\mathrm{H} 1)$, our data demonstrated that only employment status was associated with WHOQOLBref domains. No statistically significant results were obtained for age, gender, schooling, cohabitation or marital status.

With regard to being employed as a factor that improves the quality of life of patients with schizophrenia, we observed that only $9.7 \%$ of the subjects were employed. Despite the small number of employed people, the present data demonstrated that being employed was associated with higher quality of life. These results corroborate those of a number of other studies. ${ }^{15,16}$ Thus, it seems that a large percentage of individuals with schizophrenia are not satisfied with the quality of their lives, and their level of dissatisfaction differs.

As for hypotheses $\mathrm{H} 2$ and $\mathrm{H} 4$, no statistically significant results were obtained for the sample, so we cannot say that disease duration and participated in psychosocial rehabilitation programs have an influence on the quality of life of people with schizophrenia.

With regard to hypothesis $\mathrm{H} 3$, the higher the number of hospitalizations in psychiatric units, the worse the quality of life of schizophrenic patients. In the present sample, $46.3 \%$ of the participants had been hospitalized 2-5 times, while only $7.8 \%$ had never been admitted to a psychiatric unit. Among those hospitalized, 55.6\% had been hospitalized within the last 5 years. Patients who had at least one hospitalization within the last 5 years had worse results in the environmental and general domains as well as in the WHOQOL-Bref total score. Considering that hospitalizations correspond to relapses, we may conclude that patients who had a relapse requiring hospitalization within 5 years prior to data collection obtained worse results in quality of life. In this regard, a study involving 1,024 patients with schizophrenia and assessing the influence of quality of life on relapses within 24-month intervals found that quality of life can be considered a predictor of relapse in schizophrenia. ${ }^{17}$ In another study conducted in Brazil with 70 patients, those reporting previous psychiatric hospitalizations had worse quality of life results. ${ }^{18}$ In this scenario, reducing the number of hospitalizations seems to be of utmost importance in controlling the symptomatology, involving not only medication management, but also a set of psychosocial interventions that promote insight into the disease and social support.

The results regarding satisfaction with social support in this study were low in all SSSS domains. This is in line with another study in which a decrease in satisfaction with social support and an increase in loneliness were found for this population. ${ }^{19}$

In what concerns hypothesis H5, i.e., satisfaction with social support as a factor that improves the quality of life of schizophrenic patients, the data here presented point to this direction. Analyzing the results of the multiple linear regression analysis between the total WHOQOL-Bref score and the four domains of the SSSS, we found that quality of life was influenced by satisfaction with social support, in that the greater the satisfaction with friends and the greater the intimacy, the greater the quality of life. In another study conducted in Chile with 45 schizophrenic patients, subjects who showed greater perception of social support had a more positive attitude towards different aspects of quality of life, and those who received little social support were the ones with the lowest results in terms of quality of life. ${ }^{7}$ Another study with 32 subjects indicated that the higher the perception of social support, the higher the quality of life. ${ }^{20}$

We therefore believe that the social assessment of patients with schizophrenia and the existence of support networks that meet their individual needs are important and will consequently improve their quality of life. For this, rather than looking at the patient's social network, it is necessary to see if they are satisfied with their social relationships, be it with family, friends, intimacy or social activities, as dissatisfaction with social support may worsen quality of life. Professionals therefore have an increased responsibility and should be concerned with perceiving which interventions are most effective for each individual, taking into account all the factors that may influence quality of life.

Thus, the focus should be not only on reducing symptomatology - an extremely important factor -, but also on implementing strategies that involve family, friends and other important social relationships for the patient in the psychosocial rehabilitation of the latter. In addition, satisfactory social activities should be promoted, and for this reason, professionals 
should first question the patients themselves about what activities they like and take pleasure in, rather than performing the same activities with all patients. We should pay attention not only to the group, but also to the individuality of each person within the group itself.

As limitations of this study, we point out the fact that it was a cross-sectional study, which does not allow us to analyze quality of life and satisfaction with social support over a period of years, comparing changes in the same patients and taking into account all the factors involved, including the number of hospitalizations arising over a given period of time as well as changes in social and family relationships. Furthermore, this was a correlational study, so the direction of effects remains uncertain. Because schizophrenia is a serious mental illness, we may suppose this would explain unemployment and number of relapses which inevitably affect quality of life. This condition can limit quality of life even with adequate social support. More studies are needed to confirm this. Finally, another limitation of this study was the absence of data about each individual's support networks that could justify the degree of satisfaction with social support, as well as the absence of data about the presence of positive and negative symptoms, which may also be related to quality of life.

\section{Conclusion}

Being unemployed and having been hospitalized within the last 5 years were factors associated with poorer quality of life in patients with schizophrenia. Satisfaction with friends and intimacy were independently associated with quality of life: the greater the satisfaction with these factors, the higher the quality of life. The results of this study demonstrate the importance of targeting psychosocial rehabilitation interventions at patients with schizophrenia, taking into account their satisfaction with social support, the reduction of hospitalizations and the promotion of their occupational role, reinforcing not only the social support network, but also their satisfaction with it.

\section{Acknowledgements}

This work was financed by national funds from Fundação para a Ciência e Tecnologia, I.P. (FCT); project of Centro de Estudos em Educação, Tecnologias e Saúde (UID/ Multi/04016/2016). The authors are also grateful for the support provided by Instituto Politécnico de Viseu and Centro de Estudos em Educação, Tecnologias e Saúde (CI\&DETS).

We would like to thank all the health professionals involved in selecting participants and all the participants for agreeing to participate in this study.

\section{Disclosure}

No conflicts of interest declared concerning the publication of this article.

\section{References}

1. Robinson D, Woerner M, Alvir J, Bilder R, Goldman R, Geisler S, et al. Predictors of relapse following response from a first episode of schizophrenia or schizoaffective disorder. Arch Gen Psychiatry. 1999;56:241-7.

2. Chi MH, Hsiao CY, Chen KC, Lee LT, Tsai HC, Lee IH, et al. The readmission rate and medical cost of patients with schizophrenia after first hospitalization - A 10-year follow-up population-based study. Schizophr Res. 2016;170:184-90.

3. Alvarez-Jimenez M, Priede A, Hetrick SE, Bendall S, Killackey E, Parker AG, et al. Risk factors for relapse following treatment for first episode psychosis: a systematic review and meta-analysis of longitudinal studies. Schizophr Res. 2012;139:116-28.

4. Emsley R, Chiliza B, Asmal L, Harvey BH. The nature of relapse in schizophrenia. BMC Psychiatry. 2013;13:50.

5. American Psychiatric Association. Diagnostic and Statistical Manual of Mental Disorders, Fifth Edition (DSM-5). Arlington: American Psychiatric Publishing; 2013.

6. Bellack AS, Mueser KT, Gingerich S, Agresta J. Social skills training for schizophrenia: A step-by-step guide. 2nd ed. New York: Guilford; 2013.

7. Gutiérrez-Maldonado J, Caqueo-urízar A, Fernández-Dávila MFP. Influencia de la percepción de apoyo y del funcionamiento social en la calidad de vida de pacientes con esquizofrenia y sus cuidadores. Psicothema. 2012;24:255-62.

8. Boyer L, Baumstarck K, Boucekine M, Blanc J, Lançon C, Auquier P. Measuring quality of life in patients with schizophrenia: an overview. Expert Rev Pharmacoecon Outcomes Res. 2013;13:343-9.

9. Fervaha G, Agid O, Takeuchi H, Foussias G, Remington G. Clinical determinants of life satisfaction in chronic schizophrenia: data from the CATIE study. Schizophr Res. 2013;151:203-8.

10. Alessandrini M, Lançon C, Fond G, Faget-Agius C, Richieri R, Faugere $M$, et al. A structural equation modelling approach to explore the determinants of quality of life in schizophrenia. Schizophr Res. 2016;171:27-34.

11. Chou C-Y, Ma M-C, Yang T-T. Determinants of subjective healthrelated quality of life (HRQOL) for patients with schizophrenia. Schizophr Res. 2014;154:83-8.

12. Meesters PD, Comijs HC, de Haan L, Smit JH, Eikelenboom P, Beekman ATF, et al. Subjective quality of life and its determinants in a catchment area based population of elderly schizophrenia patients. Schizophr Res. 2013;147:275-80.

13. Canavarro $M C$, Simões $M R$, Vaz Serra A, Pereira M, Rijo D, Quartilho MJ, et al. WHOQOL-Bref: instrumento de avaliação da qualidade de vida da Organização Mundial de Saúde. In: Simões MR, Machado C, Gonçalves MM, Almeida LS, coord. Avaliação psicológica: instrumentos validados para a população portuguesa. Coimbra: Quarteto; 2007. p. 77-100.

14. Pais Ribeiro JL. Escala de satisfação com o suporte social. Lisboa: Placebo; 2011.

15. Üçok A, Gorwood P, Karadayı G. Employment and its relationship with functionality and quality of life in patients with schizophrenia: EGOFORS Study. Eur Psychiatry. 2012;27:422-5.

16. Othman Z, Ghazali M, Razak AA, Husain M. Severity of tardive dyskinesia and negative symptoms are associated with poor quality of life in schizophrenia patients. Int Med J. $2013 ; 20: 677-80$. 
17. Boyer L, Millier A, Perthame E, Aballea $S$, Auquier $P$, Toumi M. Quality of life is predictive of relapse in schizophrenia. BMC Psychiatry. 2013;13:15.

18. Silva TFCD, Mason V, Abelha L, Lovisi GM, Cavalcanti MT. Quality of life assessment of patients with schizophrenic spectrum disorders from Psychosocial Care Centers. J Bras Psiquiatr. 2011;60:91-8.

19. Angell B, Test MA. The relationship of clinical factors and environmental opportunities to social functioning in young adults with schizophrenia. Schizophr Bull. 2002;28:259-71.

20. Eack SM, Newhill CE, Anderson CM, Rotondi AJ. Quality of life for persons living with schizophrenia: more than just symptoms. Psychiatr Rehabil J. 2007;30:219-22.

\section{Correspondence:}

Lara Manuela Guedes de Pinho

Departamento de Educação e Psicologia

Centro de Investigação "Didática e Tecnologia na Formação de Formadores" (CIDTFF)

Centro de Investigação em Tecnologias e Serviços de Saúde (CINTESIS)

Universidade de Aveiro

3810-193 - Aveiro, Portugal

E-mail: larapinho7@gmail.com

Tel. : +00351916545031 